\title{
Upcycling strategies for waste electronic and electrical equipment based on material flow analysis
}

\author{
Sora $\mathrm{Yi}^{1^{\dagger}}$, Hisun $\mathrm{Lee}^{1^{\dagger}}$, Jeongmin $\mathrm{Lee}^{1}$, Woong $\mathrm{Kim}^{2^{+}}$ \\ ${ }^{1}$ Department of Living Environment Research, Korea Environment Institute, Sejong 30147, Republic of Korea \\ ${ }^{2}$ Department of Environmental Engineering, Kyungpook National University, Daegu 41566, Republic of Korea
}

\begin{abstract}
Upcycling generally refers to the conversion of waste materials to something useful or valuable and is a useful concept that can be applied not only to the waste design industry but also to waste recycling and resource circulation. Our study highlights upcycling as the key concept for improving the value of waste by redefining the concept as "the recycling of waste materials and discarded products in ways that enhance their value." Four upcycling strategies are linked to material flow analyses conducted on waste electronic and electrical equipment, specifically waste refrigerators and waste computers, to examine the technologies available for implementation and suggest guidelines for the promotion of upcycling. The amount of waste refrigerators collected by the formal sector was 121,642 tons/y and the informal sector, 63,823 tons $/ y$. The current recycling ratio of waste refrigerators was estimated as $88.53 \%$. A total of 7,585 tons/y of waste computers were collected by the formal sector and 3,807 tons/y by the informal sector after discharge. Meanwhile, the current recycling ratio of waste computers was estimated as $77.43 \%$. We found that it is possible to introduce 28 upcycling technologies in the case of refrigerators, and 15 technologies are available to promote upcycling in the case of computers. By refining the broad concept of upcycling and looking at the stages of material flow, our approach presents universally applicable directions for incorporating upcycling in resource recovery and recirculation plans.
\end{abstract}

Keywords: High-grade recycling, Resource circulation, Waste computer, Waste refrigerator

\section{Introduction}

Higher standards of living and technological development, especially in the electric and electronic industry, have shortened the product cycle of electrical and electronic products, leading to an overall increase of waste electronic and electrical equipment (WEEE) [1]. At the same time, the rise in the prices of raw metal has brought considerable attention to the recovery of valuable metals, such as copper, zinc, nickel, etc., included in WEEE. Korea has recently introduced a recycling target management system for WEEE and set a target for recycling per capita (6.0 kg per person) to be met by 2018. These developments have increased the demand for research on resource circulation and recycling, especially concerning the promotion of WEEE recycling [2].

One concept that has been gaining importance in WEEE re- cycling is upcycling. Upcycling is a combination of the words 'upgrade' and 'recycling' and is presently used to refer to the creation of products with added value using recycled materials [2]. Our study focuses on upcycling as the key concept for improving the value of WEEE by refining the broad use of the concept into a practically applicable definition and suggesting strategies to promote upcycling based on domestic and foreign case studies. Then, the material flows of WEEE are analysed, specifically on valuable resources and low-value residues that can be obtained from discarded refrigerators and computers [2, 3], including the quantities of recovered resources and final throughputs. Based on the results of the material flow analysis (MFA), we examine the available upcycling technologies for recovering and recirculating resources from waste refrigerators and computers and review how upcycling can be more effectively promoted in terms of the four strategies and the stages of material flow.
This is an Open Access article distributed under the terms of the Creative Commons Attribution Non-Commercial License (http://creativecommons.org/licenses/by-nc/3.0/) which permits unrestricted non-commercial use, distribution, and reproduction in any medium, provided the original work is properly cited.

Copyright (C) 2019 Korean Society of Environmental Engineers
Received March 8, 2018 Accepted June 11, 2018

${ }^{\dagger}$ Corresponding author

Email: sryi@kei.re.kr, leehs@kei.re.kr, elshine@knu.ac.kr

Tel: +82-44-415-7807 Fax: +82-44-415-7644

ORCID: 0000-0003-2667-8955 (W. Kim) 
Table 1. List of Sources or Companies for the MFA of Waste Refrigerators and Computers

\begin{tabular}{lcc}
\hline \multirow{2}{*}{ Step } & Waste refrigerators & Source of materials \\
\cline { 2 - 3 } & KECO internal data in the Eco-Assurance System of Electrical and Electronic Equipment and Vehicles (EcoAS) \\
\hline Discarding / collection & Recycling center (Yongin city) & Recycling center (Yongin city) \\
Pre-treatment & A (Compressor facility) & G (Guri city) \\
Resource recovery / & C (Hwasung city) & J (Namyangju city) \\
raw material production & G (Guri city) & \\
\hline
\end{tabular}

\section{Materials and Methods}

Herein, we look specifically at the WEEE from refrigerators and computers to conduct an MFA based on previous studies $[4,5]$ and the internal materials of Korea Environment Corporation (KECO) on WEEE release/import and purchase/sale data for 2015 [6]. The 2015 data from KECO was used as this is the first year in which the Korea government expanded its free waste collection policy (collecting waste products from homes without cost) nation-wide [1]. The MFA of WEEE was classified into the following stages: discharge, collection, pre-treatment, resource recovery, and sale/export/disposal [3]. Table 1 shows the lists of sources or companies used for the MFA of waste refrigerators and computers. Additional data and information were collected through interviews with WEEE recycling associations and recycling industry experts, consultations with the Ministry of Environment and KECO, and field surveys conducted at WEEE recycling centers and companies. We also reviewed existing literature on WEEE recycling and MFA as well as case studies on upcycling in the European Union (EU) and Japan. For the MFA of waste refrigerators and computers, we used STAN (short for subSTance flow ANalysis) software that supports material flow analysis. From the results of MFA, we reviewed the applicable technologies available for improving the recovery and recycle of materials from waste refrigerators and computers.

\section{Results and Discussion}

\subsection{Upcycling in Korea and Overseas}

Our comparative study of WEEE recycling and recovery policies in the EU, Japan, and Korea showed that EU has the highest target set for WEEE recycling and recovery rate, although the targets set by South Korea and Japan are close to that of the EU. Also, a notable trend in the EU and Japan is the use of the terms 'recovery rate' and 're-commercialization rate' to induce greater high-grade and advanced recycling.

To refine the concept of upcycling, we conducted domestic and foreign case studies on upcycling. We found that in Korea, upcycling can be categorized into "waste upcycling for value creation" and "upcycling using design elements." On upcycling in countries other than Korea, we looked into the re-commercializa- tion standards as defined in Japan's legislation on recycling of home appliances and other literature [7-9]. According to a domestic study, upcycling is defined as follows: "if the existing concept of recycling revolves around producing recycled material that continues to lose value, i.e., downcycling, upcycling is a concept of recycling that realizes cradle-to-cradle resource use by enhancing the value of waste through recycling" [8]. In another study, upcycling is defined as "the process of converting waste materials into something useful and more valuable" [9].

Based on these examinations, for our study, we define the concept of upcycling for WEEE as "the enhancement of the value of waste material or discarded products through the recycling process." This definition enables us to suggest the four strategies for promoting upcycling, specifically: (1) the conversion of existing low-grade recycling products into high-grade or advanced recycling, (2) the recycling of products or items that are simply being discarded (landfill or incineration without energy recovery), (3) the conversion of energy recovery recycling into material recovery recycling, and (4) the improvement of recycling productivity or efficiency.

\subsection{MFA of Waste Refrigerators and Computers}

Waste refrigerators and waste computers are collected using different methods by the formal and informal sectors. WEEE collection by the formal sector refers to the free collection operated by the central and local governments, reverse collection (mandatory producer or product distributor), or waste collection/transportation/ recycling companies. On the other hand, the informal sector includes junk shops, private collectors, or reuse shops. The formal and informal sectors were classified according to the data input system of the Eco-Assurance System of Electrical and Electronic Equipment and Vehicles (EcoAS). We conducted MFAs of waste refrigerators and computers for the five stages of discharge, collection, pre-treatment, resource recovery, and sale/export/disposal.

\subsubsection{MFA of waste refrigerators}

The amount of waste refrigerators collected by the formal sector was 121,642 tons/y and the informal sector, 63,823 tons/y [6]. According to Recycling Center (RC) interview and internal materials (2016), discarded refrigerators can be converted into scrap, plastic, urethane, etc. in the pre-treatment stage, which involves disassembly, separation of the waste refrigerant, shredding, and separation. In the formal sector as shown in Fig.1., the estimated 
amounts of scrap, plastics, PCB, cable, glass, waste refrigerant recovered through disassembly were 12,506 tons/y, 12,506 tons/y, 395 tons/y, 658 tons/y, 19,747 tons/y, and 790 tons/y, respectively. The amount of urethane recovered by shredding was 13,165 tons/y, while the amounts of metal, nonferrous and plastics were recovered through separation were 52,659 tons/y, 1,975 tons/y, and 7,241 tons/y, respectively.

We estimated the amount of resources recovered from waste refrigerators by the informal sector based on interviews with junk shops. The areal range of collection of one junk shop was obtained based on the interviews, then the population ratio of the collection area was calculated by comparing the population in Seoul and the national population. The daily scale of operations of one junk shop, the average weight of a refrigerator, number of working days of the junk shop ( $5 \mathrm{~d}$ a week or $250 \mathrm{~d}$ a year) were taken into consideration in the calculation (A Junk shop interview and internal materials, 2016). Our calculations showed that in the informal sector, the amounts of waste refrigerant, plastics (shelf), glass (door), and compressor recovered by dismantling the exterior of a refrigerator were 414 tons/y, 6,542 tons/y, 10,360 tons/y, and 6,562 tons/y, respectively. After dismantling, 27,629 tons/y of scrap iron, 345 tons/y of copper, 3,799 tons/y of ABS/PP/PE, 691 tons/y of nickel silver, 345 tons/y of cable, 207 tons/y of boards, and 6,907 tons $/ y$ of urethane were recovered through shredding. However, we were unable to obtain the amount of waste refrigerators that were reused.

After resource recovery, valuable resources such as copper, scrap, metal, and plastics are sold or exported to recycling companies, and low-value residues such as oils, waste refrigerant, and urethane are disposed to landfills or incinerated. Table 2 shows the final recycling amount and ratio of waste refrigerators for the formal sector. 121,642 tons/y of waste refrigerators were collected, of which 107,687 tons/y were recycled and 13,955 tons/y of residues were disposed. Overall, $88.53 \%$ of waste refrigerators were recycled in 2015. The MFA uncovered that among the collected resources, urethane was inactively recycled, and a part of the waste refrigerant was released into the atmosphere. With more active recycling of urethane, it will be possible to recycle most of the resources from waste refrigerators collected by both the formal and informal sectors.

Table 2. The Final Recycling Amount and the Ratio of Waste Refrigerators for the Formal Sector

\begin{tabular}{lc}
\hline Category & Amount/recycling ratio \\
\hline Collection & 121,642 tons/y \\
Recycling & 107,687 tons/y \\
Residue & 13,955 tons $/ y$ \\
Recycling ratio & $88.53 \%$ \\
\hline
\end{tabular}

\subsubsection{MFA of waste computers}

A total of 7,585 tons/y of waste computers were collected by the formal sector and 3,807 tons/year by the informal sector after discharge. The amount of waste computers collected by the informal sector was estimated based on J Junk shop interview and internal materials (2016), which came to be about $34.4 \%$ per year. The stages of processing waste computers for resource recovery are the same as those of waste refrigerators. Through pre-treatment such as separation, shredding, and extraction, waste computers are converted metal, nonferrous, plastics, glass, etc. In the formal sector, as shown in Fig. 2, the amount of metal, nonferrous, plastics, glass, and residues recovered by separation, shredding and separation was 6,826 tons/y. 759 tons/y of plastics, nonferrous, precious metal residues were also recovered by shredding and extraction. In the informal sector, 1,983 tons/y of recyclable parts were acquired by separation, and 1,701 tons/y of scrap iron, cable, plastics, and valuable materials were recovered by shredding and separation.

After the resource recovery stage, valuable resources such as metal, nonferrous, plastics and recyclable parts are sold or exported to recycling companies, and low-value residues are disposed to landfills or incinerated. Table 3 shows the final recycling amount and ratio of waste computers for the formal sector. Of the 7,585 tons/y of waste computers that were collected, 5,873 tons/y were recycled and 1,712 tons/y were disposed of as residue. The recycling ratio of waste computers in 2015 was $77.43 \%$. The MFA of waste computers revealed that among the collected resources, glass and some metals contained in monitors were either landfilled or incinerated, pointing to the need for new technologies for recycling liquid crystal glass and other metal resources.

Table 3. The Final Recycling Amount and the Ratio of Waste Computers for the Formal Sector

\begin{tabular}{lc}
\hline Category & Amount/recycling ratio \\
\hline Collection & 7,585 tons $/ \mathrm{y}$ \\
Recycling & 5,873 tons/y \\
Residue & 1,712 tons $/ y$ \\
Recycling ratio & $77.43 \%$ \\
\hline
\end{tabular}

\subsection{Possible Implementation of Upcycling Technologies Based on MFA: A Review}

Based on the results of the MFA, we examined the upcycling technologies available for recovering and recirculating resources from waste refrigerators and computers. In doing so, we linked foreign recycling technologies [10-14] with the four upcycling strategies proposed herein. We limited the scope of our examination to the formal sector. Fig. 1 presents the upcycling technologies available for implementation based on the MFA for waste refrigerators. In case of refrigerators, it is possible to introduce 28 upcycling technologies. Among these, 13 technologies are applicable for converting existing low-grade recycling products into high-grade or advanced recycling, 9 technologies are geared toward improving the productivity or efficiency of recycling, 5 technologies are for recycling products or items that are simply being discarded (landfill or incineration without energy recovery). The one remaining technology is for converting energy recovery recycling to material recovery recycling.

Fig. 2 illustrates the upcycling technologies available for implementation based on the MFA of waste computers. In the case of computers, 15 technologies are available, among which 8 technologies are applicable for upgrading low-grade recycling products 


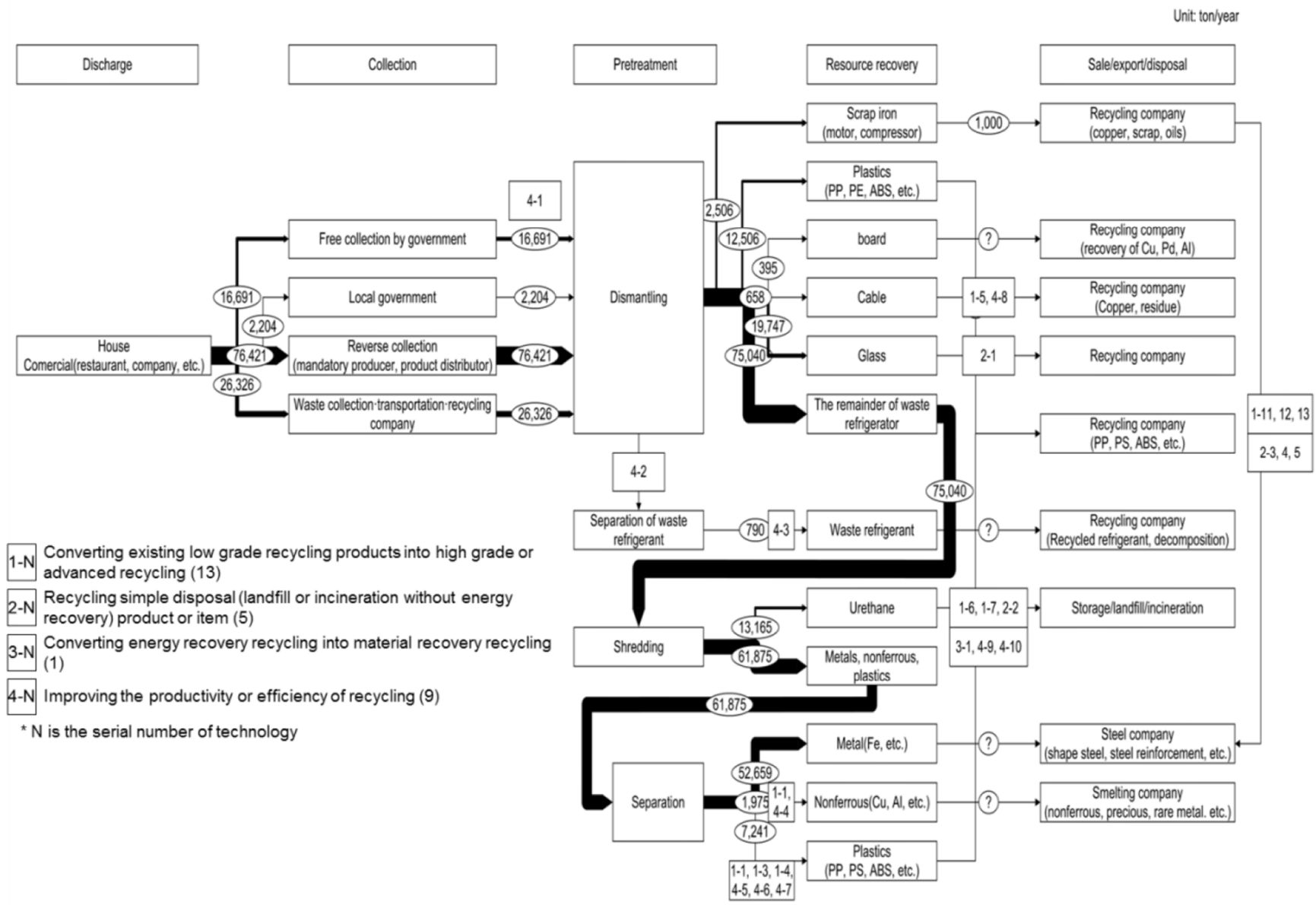

Fig. 1. Upcycling technologies available for implementation based on the MFA of waste refrigerators.
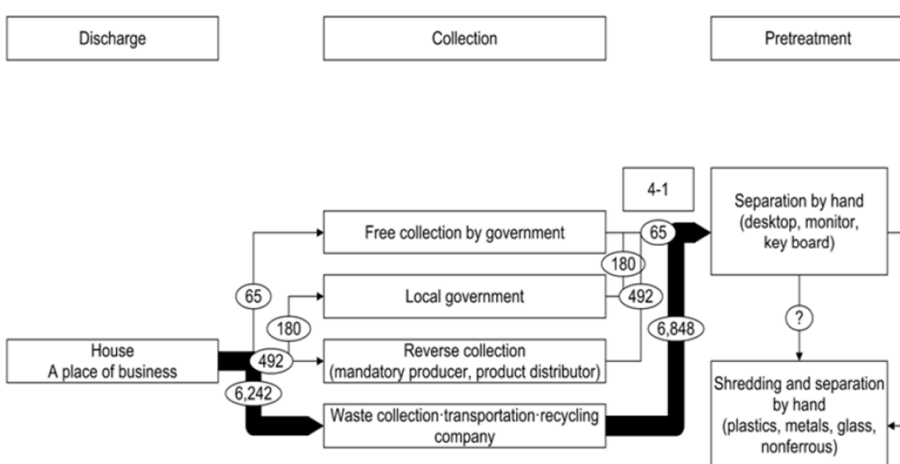

Unit: ton/year

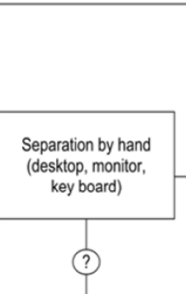

Shredding and separation

by hand by hand
(plastics, metals, glass, nonferrous)

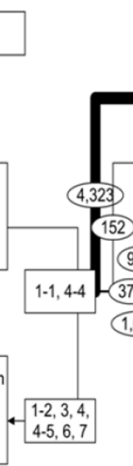

$?$

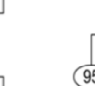

1-N Converting existing low grade recycling products into high grade or Shredding-extraction(high

2-N Recycling simple disposal (landfill or incineration without energy temperature, wet proces
PCB board

2-N Recycling simple disposal (land

3-N Converting energy recovery recycling into material recovery recycling (1)

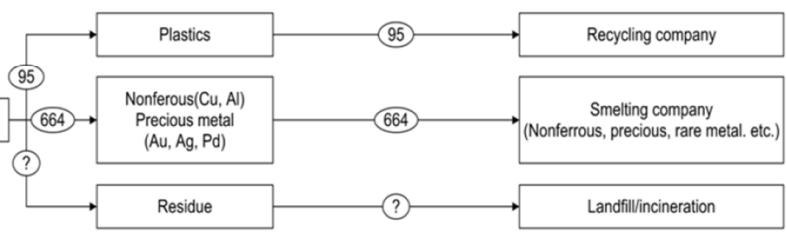

4-N Improving the productivity or efficiency of recycling (9)

${ }^{*} \mathrm{~N}$ is the serial number of technology

Fig. 2. Upcycling technologies available for implementation based on the MFA of waste computers. 
Table 4. Available Upcycling Technologies for Refrigerators and Computers at Each Stage of Waste Treatment

\begin{tabular}{|c|c|c|c|}
\hline Stage & Type & Upcycling technology & Achievements and expected effects \\
\hline \multirow[b]{3}{*}{ Pre-treatment } & $4-1$ & Mixed treatment line for refrigerators & - Improve work efficiency and use of space \\
\hline & $4-2$ & Improvement in Freon management & $\begin{array}{l}\text { - Prevent Freon leakage by implementing a continuous monitoring } \\
\text { system for Freon concentration } \\
\text { - Automatically notifies authorities to enable immediate response } \\
\text { when a temperature abnormality occurs due to a cooler failure, } \\
\text { etc. after work or during holidays }\end{array}$ \\
\hline & $1-14$ & $\begin{array}{l}\text { Technology for recovering different } \\
\text { types of electronic circuits such as tan- } \\
\text { dem capacitors from discarded printed } \\
\text { circuit boards }\end{array}$ & $\begin{array}{l}\text { - Above } 80 \% \text { pure tantalum* capacitors can be recovered from mixed } \\
\text { electronic circuit waste } \\
\text { - Multicomponent mixtures containing mixed electronic circuits, } \\
\text { at least two screening steps are required to recover the medium } \\
\text { specific gravity particles } \\
\text { - High, medium, and high specific gravity particles can be recovered, } \\
\text { and high purity resources can be recovered by precise sorting } \\
\text { * One of the most expensive rare metals, apart from precious metals }\end{array}$ \\
\hline \multirow{5}{*}{$\begin{array}{l}\text { Resource re- } \\
\text { covery }\end{array}$} & $4-3$ & Freon decomposition treatment & $\begin{array}{l}\text { - Decomposes recovered Freon to prevent harm from Freon leakage } \\
\text { and contribute to energy saving }\end{array}$ \\
\hline & $\begin{array}{l}1-1 \\
4-4\end{array}$ & $\begin{array}{l}\text { Advanced technology for separating } \\
\text { copper and aluminium based on color } \\
\text { identification }\end{array}$ & $\begin{array}{l}\text { - Possible to recover 95\% pure copper } \\
\text { - Before implementation, copper and aluminium was separated by } \\
\text { hand: implementing mechanical sorting improved work environ- } \\
\text { ment }\end{array}$ \\
\hline & $\begin{array}{l}1-2 \\
4-5\end{array}$ & $\begin{array}{l}\text { Sorting mixed plastic using oscillation } \\
\text { and wind power }\end{array}$ & $\begin{array}{l}\text { - Reduction of foreign matter in mixed plastics from } 37 \% \text { to } 4 \% \\
\text { - Reduction of the number of workers from } 6 \text { to } 1\end{array}$ \\
\hline & $\begin{array}{l}1-3 \\
4-6\end{array}$ & $\begin{array}{l}\text { Sorting mixed plastic using the differ- } \\
\text { ence of specific gravity }\end{array}$ & $\begin{array}{l}\text { - Recovers high quality materials by combining the use of specific } \\
\text { gravity and water pressure, (primary recovery: PP resin; secondary } \\
\text { recovery: PS resin) }\end{array}$ \\
\hline & $\begin{array}{l}1-4 \\
4-7\end{array}$ & $\begin{array}{l}\text { Simultaneous sorting device for three } \\
\text { types of plastics using near infrared } \\
\text { sensors }\end{array}$ & $\begin{array}{l}\text { - Practical application of a simultaneous sorting device for three } \\
\text { kinds of plastic by controlling air flow to reduce flotation difference } \\
\text { and using high-speed, high-precision selective air discharge tech- } \\
\text { nology } \\
\text { - The three sorting processes are performed in one step, doubling } \\
\text { the processing efficiency }\end{array}$ \\
\hline \multirow{6}{*}{$\begin{array}{c}\text { Product } \\
\text { Manufacture }\end{array}$} & $\begin{array}{l}1-5 \\
4-8\end{array}$ & $\begin{array}{l}\text { Wire processing equipment (for effi- } \\
\text { cient separation of copper and wire } \\
\text { coating) }\end{array}$ & $\begin{array}{l}\text { - Can recover almost } 100 \% \text { pure copper, contributing to the reuse } \\
\text { of resource with greater added value } \\
\text { - The recovered wiring can be put into the device as is, improving } \\
\text { work efficiency }\end{array}$ \\
\hline & $2-1$ & $\begin{array}{l}\text { Recovery of refrigerator vacuum in- } \\
\text { sulation panels (VIP) (Refrigerator VIP } \\
\text { laser processing machine) }\end{array}$ & $\begin{array}{l}\text { - By singling out and recovering the glass fibers of VIP: Prevents safety/hy- } \\
\text { giene hazards, extends lifespan of grinder filter, enhances recycling } \\
\text { of VIP (resource circulation system currently under review) }\end{array}$ \\
\hline & $\begin{array}{l}2-2 \\
4-9\end{array}$ & $\begin{array}{l}\text { Conversion of urethane insulation into } \\
\text { solid fuel }\end{array}$ & $\begin{array}{l}\text { - Successful in evaporating almost all Freon contained in the ure- } \\
\text { thane and reducing the volume to } 1 / 3\end{array}$ \\
\hline & $\begin{array}{l}1-6 \\
3-1\end{array}$ & $\begin{array}{l}\text { Commodification of recycled re- } \\
\text { frigerator urethane }\end{array}$ & $\begin{array}{l}\text { - Recovered high purity polyurethane foam can be used as building } \\
\text { materials (insulation board) }\end{array}$ \\
\hline & $\begin{array}{c}1-7 \\
4-10\end{array}$ & $\begin{array}{l}\text { Refrigerator urethane foam pelletizing } \\
\text { device (achieving almost } 100 \% \text { emulsi- } \\
\text { fication by pelletization) }\end{array}$ & $\begin{array}{l}\text { - Stable operation in place since April 2013, continuously achieving } \\
\text { almost } 100 \% \text { emulsification } \\
\text { - Significant reductions in urethane volume, reducing } \mathrm{CO}_{2} \text { emissions } \\
\text { from transport (approx. 1/4) }\end{array}$ \\
\hline & $1-8$ & $\begin{array}{l}\text { Develop technologies for expanding } \\
\text { the usage of recycled plastics }\end{array}$ & $\begin{array}{l}\text { - Can recover almost } 100 \% \text { pure copper, contributing to the reuse } \\
\text { of resource with greater added value } \\
\text { - The recovered wiring can be put into the device as is, improving } \\
\text { work efficiency }\end{array}$ \\
\hline
\end{tabular}




\begin{tabular}{|c|c|c|c|}
\hline Stage & Type & Upcycling technology & Achievements and expected effects \\
\hline \multirow{8}{*}{$\begin{array}{c}\text { Product } \\
\text { Manufacture }\end{array}$} & $1-9$ & $\begin{array}{l}\text { Develop and implement self-circulat- } \\
\text { ing recycling technology that re- } \\
\text { peatedly reuses plastics }\end{array}$ & $\begin{array}{l}\text { - By singling out and recovering the glass fibers of VIP: Prevents safe- } \\
\text { ty/hygiene hazards, extends lifespan of grinder filter, enhances re- } \\
\text { cycling of VIP (resource circulation system currently under review) }\end{array}$ \\
\hline & $1-10$ & $\begin{array}{l}\text { Develop and implement closed materi- } \\
\text { al recycling technology that repeatedly } \\
\text { reuses plastics }\end{array}$ & $\begin{array}{l}\text { - Not only general characteristics such as impact resistance but } \\
\text { also flame retardancy can be recovered in recycled materials to } \\
\text { the same level as new materials }\end{array}$ \\
\hline & $\begin{array}{c}1-11 \\
2-3\end{array}$ & $\begin{array}{l}\text { Recovery of neodymium magnet from } \\
\text { compressors (Case 1) }\end{array}$ & $\begin{array}{l}\text { - Economical neodymium magnet recovery by automating the motor } \\
\text { dismantling process } \\
\text { - Recovered neodymium magnet can be refined by a magnet manu- } \\
\text { facturer into new neodymium or dysprosium to be used in manu- } \\
\text { facturing electronic products }\end{array}$ \\
\hline & $\begin{array}{c}1-12 \\
2-4\end{array}$ & $\begin{array}{l}\text { Recovery of neodymium magnet from } \\
\text { compressors (Case 2) }\end{array}$ & $\begin{array}{l}\text { - Neodymium magnet recovery system with small, low-cost equip- } \\
\text { ment configuration for each process } \\
\text { - Cooperate with magnetic material and magnet manufacturers to } \\
\text { circulate rare-earth elements (REE) }\end{array}$ \\
\hline & $\begin{array}{l}1-13 \\
2-5\end{array}$ & $\begin{array}{l}\text { REE magnet recovery device } \\
\text { (Automatic disassembly of REE mag- } \\
\text { nets from used air conditioners) }\end{array}$ & $\begin{array}{l}\text { - Automatically disassembles the magnet from the air conditioner } \\
\text { compressor motor (rotor) in room temperature conditions for REE } \\
\text { magnet disassembly } \\
\text { - In conjunction with the existing compressor disassembly line, } \\
\text { the automatic dismantling device (which makes better use of space } \\
\text { and labor) recovers REE magnets efficiently }\end{array}$ \\
\hline & $2-6$ & $\begin{array}{l}\text { Conversion of CRT glass into glass fi- } \\
\text { bers }\end{array}$ & $\begin{array}{l}\text { - Recycled glass from CRT TVs can be used as materials for re- } \\
\text { frigerators } \\
\text { - Use as material for the vacuum insulation panel in newly-manufac- } \\
\text { tured refrigerators to reduce the energy required to obtain vacuum } \\
\text { insulation materials and produce energy-saving refrigerators }\end{array}$ \\
\hline & $2-7$ & $\begin{array}{l}\text { Develop new purification material } \\
\text { (zeolite) using LCD panel glass }\end{array}$ & $\begin{array}{l}\text { - Products in development are new materials that combine the fea- } \\
\text { tures and functionality of LCD panel glass such as resistance to } \\
\text { heat, abrasion, and corrosion, which are expected to be in greater } \\
\text { demand in the future }\end{array}$ \\
\hline & $2-8$ & $\begin{array}{l}\text { Develop high performance paint from } \\
\text { LCD panel glass }\end{array}$ & $\begin{array}{l}\text { - Minimizes disposal of disposed glass materials } \\
\text { - Possible to improve durability in outdoor installations that are } \\
\text { exposed to sunlight, rain, sand, etc. } \\
\text { - LED lighting applied with this paint has been receiving great domes- } \\
\text { tic and international responses }\end{array}$ \\
\hline
\end{tabular}

into high-grade or advanced recycling, 4 technologies can improve the productivity or efficiency of recycling, and 3 technologies are for recycling simply discarded products or items.

Table 4 comprehensively presents the available upcycling technologies for refrigerators and computers [10-14]. Other than the technologies which can also be applied to refrigerators, the applicable technologies for waste computers are mostly for recycling liquid crystal glass and substrates. Also, it was found that to induce more active upcycling, priority should be given to introducing technologies for upgrading existing low-grade recycling products into high-grade or advanced recycling.

\subsection{Guidelines for Upcycling Strategies}

Through our investigation, we were able to identify how upcycling can be more effectively promoted. Accordingly, as illustrated in Fig. 3, we propose the following guidelines for each upcycling strategy. (1) To convert low-grade recycling into high-grade or advanced recycling, higher requirements should be set for resource recovery. For example, requirements can be set so that recovered copper should be above 95\% purity; foreign matter in mixed plastics should be reduced by more than 30\%; and 100\% pure copper should be obtained from electric cables. In the case of urethane, its volume could be reduced more than one-third of its original volume by converting it into pellets which can be sold for profit. (2) Concerning the recycling of products or items that are simply disposed of (landfilled or incinerated without energy recovery), the goal should be to recover and recycle resources that cannot be recovered using existing treatment processes such as urethane-to-solid fuel, etc. by developing and introducing new technologies. Also, more efforts should be placed on developing technologies for recycling materials that have recently become common in the product manufacturing stage such as the vacuum 


\section{Upcycling Strategies}

Converting existing low grade

1 recycling products into high grade or advanced recycling

Recycling simple disposal (landfill

2 or incineration without energy recovery) product or item

Improving the productivity or efficiency of recycling

Converting energy recovery

3 recycling into material recovery recycling
Fig. 3. Guidelines for upcycling strategies.

insulation panels that are being applied to enhance the insulation and use of space in new refrigerators, etc. (3) For the conversion of energy recovery recycling to material recovery recycling, the immediate task should be to recycle recovered resources into a newly-purposed product, for instance, using recovered urethane as construction material. (4) Lastly, recycling productivity or efficiency could be improved by reducing the number of staff (e.g., a $50 \%$ reduction) and the number of operations (e.g., a $50 \%$ reduction), with the target to bring a two-fold increase in treatment efficiency or $\mathrm{CO}_{2}$ emission reduction (i.e., a $50 \%$ reduction).

Additionally, we make the following suggestions for improving each stage of waste resource circulation (discharge, collection, pre-treatment, resource recovery, and sale/export/disposal) to promote the upcycling of WEEE resources. In the discharge and collection, especially in the case of WEEE, their recycling efficiency and upcycling depend on whether the WEEE is sent to the appropriate facilities according to their state. Therefore, the waste sorting system at collection facilities and agents could be improved to ensure that items for high-grade recycling among the collected WEEE are properly determined and separated from items for simple recycling.

In the pre-treatment stage, which includes dismantling, shredding, and sorting processes, the efficiency is currently too low that it is deterring the efficiency of resource recovery in the later stages. Thus, investments should be concentrated on developing and introducing new shredding and sorting technologies. Specifically, the three processes could be improved by the application of advanced technologies for improving recycling productivity or efficiency, while the sorting process could be enhanced further by introducing technologies for converting low-grade recycling products to advanced or high-grade recycling. Also, by enforcing the obligation to improve the environmentally friendliness of product materials, it would be possible to induce manufacturers to provide precise information on the precise materials used in their

\section{Upcycling Guidelines}

- Cooper: Recover above 95\% purity

- Mixed plastic: Reduce mixing of foreign matter by more than $30 \%$

- Electric cable: Obtain $100 \%$ pure copper

- Urethane: Reduce more than one-thirds of the volume, $100 \%$ of the pellets sold for profit

- Recover and recycle resources that cannot be recovered using existing treatment processes (e.g., urethane-to-solid fuel, etc.)

- Develop recycling technology for new materials (e.g., vacuum insulation panel for refrigerators, etc.)

- Recycle recovered resource into a newly-purposed product (e.g., use urethane as construction material)

- Reduce the number of staff (e.g., a $50 \%$ reduction)

- Reduce the number of operations (e.g., a $50 \%$ reduction)

- Realize a two-fold increase in treatment efficiency

- Reduce $\mathrm{CO}_{2}$ emission (e.g., a $50 \%$ reduction) products to recycling agents and to create more sustainable products from the design phase.

In the resource recovery stage, we suggest implementing the technologies for recycling simply disposed of items and converting energy recovery recycling to material recovery recycling to promote upcycling. In addition, the policies related to resource recovery could be reviewed, especially regarding the recycling standards, to enhance the effectiveness of the four upcycling strategies. For instance, because waste-to-energy incineration of urethane is not recognized as recycling, most of the urethane from waste refrigerators is being simply disposed of despite the large percentage it takes up as WEEE. Thus, there is a need to recognize the energy recovery from waste urethane as recycling by amending the relevant recycling standard. On the other hand, what differs waste computers from waste refrigerators is that they can be reused as a whole or as parts. However, despite the separate standards for reuse and recycling rates in place, the statistics on the WEEE from waste computers are being computed only in terms of recycling rate in reality, that is, the reuse rate is not taken into account. Therefore, we recommend revising current standards for waste computers and their parts to recognize the reuse of waste computers and their parts into the recycling rate.

Lastly, the sale/export/disposal stage could benefit from the introduction of new technologies for converting existing low-grade recycling products into high-grade or advanced recycling and recycling simple disposal products or items, especially for recovering rare-earth metals from the motor of electronic appliances. With the appropriate technologies, it would become possible to increase the value of the recovered WEEE resources.

\section{Conclusions}

Upcycling can be applied not only to the waste design industry 
but also to waste recycling and resource circulation. We defined upcycling as "the enhancement of the value of waste material or discarded products through the recycling process" and suggested four upcycling strategies based on domestic and foreign case studies. Specifically, the strategies were classified into: (1) the conversion of existing low-grade recycling products into high-grade or advanced recycling, (2) the recycling of products or items that are simply being discarded (landfill or incineration without energy recovery), (3) the conversion of energy recovery recycling into material recovery recycling, and (4) the improvement of recycling productivity or efficiency. The current recycling ratios of waste refrigerators and waste computers were estimated to be $88.53 \%$ and $77.43 \%$, respectively. Also, we found that it is possible to introduce 28 upcycling technologies in the case of refrigerators, and 15 technologies are available to promote upcycling in the case of computers. The broad concept of upcycling makes it difficult to present a specific criterion for upcycling in terms of products or materials, and it is also unlikely that a quantitative target or high degree of resource recovery can be achieved by simply applying highly sophisticated upcycling technologies. Therefore, the four universally applicable strategies we propose can be a solid foundation for incorporating upcycling in resource recovery and recirculation plans, based on which strategic promotion plans can be implemented at different stages of material flow.

\section{Acknowledgments}

This study was financially supported by the Korea Environment Institute (KEI) as a project on the Activation Plan for Waste Electronic and Electrical Equipment (WEEE) Upcycling based on an Analysis of Waste Resources Circulation Flow and the National Research Foundation of Korea (NRF) grant funded by the Korea government (MSIP) (No. 2017R1A4A1015628).

This article was presented at the 2017 International Environmental Engineering Conference (IEEC2017) held on 15-17 November 2017, Jeju, Korea.

\section{References}

1. Yi S, Lee HS, Lee JM. Material flow analysis for waste re- frigerators to promote resource circulation and upcycling. J. Korea Soc. Waste Manag. 2017;34:705-712.

2. Lee HS, Yi S, Han SW, Lim HS, Lee JM. A study on activation plan of upcycling through analysis of waste resources circulation flow of waste electronic and electrical equipment (WEEE). Korea Environment Institute; 2016.

3. Lee HS, Joo HS, Jo JH, Lee JM. A study on analysis of waste resources circulation flow of end of life vehicles. Korea Environment Institute; 2015.

4. Korea Environment Institute. Study of the improvement of metal resources through material flow analysis $(\mathrm{Cu}, \mathrm{Ni})$. Ministry of Environment; 2012.

5. Lee HS, Lee JM, Lee JC, Yi S. Material flow analysis of waste resources circulation flow to enhance the circulation of metal resource: Cobalt and palladium. J. Korea Soc. Waste Manag. 2016;33:674-682.

6. Korea Environment Corporation (KECO) interview and internal materials; 2016.

7. Japan Association for Electric Home Appliances. Recycling annual report of electric home appliances 2015. Japan Association for Electric Home Appliances; 2016. p. 97-101.

8. Park SM. New mainstream of eco-friendly management: C2C (Cradle to Cradle). SERI Management note, Samsung Economic Research Institute; 2010.

9. Gong J, Liu J, Wen X, et al. Upcycling waste polypropylene into graphene flakes on organically modified montmorillonite. Ind. Eng. Chem. Res. 2014;55:4173-4181.

10. Japan Association for Electric Home Appliances. Recycling annual report of electric home appliances 2014. Japan Association for Electric Home Appliances; 2015. p. 52-66.

11. Japan Association for Electric Home Appliances. Recycling annual report of electric home appliances 2013. Japan Association for Electric Home Appliances; 2014. p. 44-52.

12. Japan Association for Electric Home Appliances. Recycling annual report of electric home appliances 2012. Japan Association for Electric Home Appliances; 2013. p. 38-57.

13. Japan Association for Electric Home Appliances. Recycling annual report of electric home appliances 2011. Japan Association for Electric Home Appliances; 2012. p. 36-45.

14. Japan Association for Electric Home Appliances. Recycling annual report of electric home appliances 2010. Japan Association for Electric Home Appliances; 2011. p. 46-65. 